\title{
Preparation of carboxymethyl cellulose based microgels for cell encapsulation
}

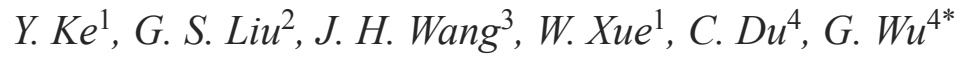 \\ ${ }^{1}$ Department of Biomedical Engineering, College of Life Science and Technology, Jinan University, 510632 Guangzhou, \\ China \\ ${ }^{2}$ Department of Pediatrics, Institute of Fetal-Preterm Labor Medicine, The First Affiliated Hospital, Jinan University, \\ 510632 Guangzhou, China \\ ${ }^{3}$ National Engineering Research Center for Tissue Reconstruction and Restoration, 510006 Guangzhou, China \\ ${ }^{4}$ Biomaterial Research Institute, School of Materials Science and Engineering, South China University of Technology, \\ 510641 Guangzhou, China
}

Received 8 April 2014; accepted in revised form 13 June 2014

\begin{abstract}
Biocompatible and biodegradable carboxymethyl cellulose (CMC) has been modified with 4-hydroxybenzylamine (CMC-Ph) in order to prepare CMC-based microgels through the horseradish peroxidise/hydrogen peroxide enzymatic reaction. $\mathrm{CMC}-\mathrm{Ph}$ was identified as a blend, and the amount of the grafted 4-hydroxybenzylamine per 100 units of CMC was between 17 and 23 according to the molecular weight of CMC. Through a special designed co-flowing microfluidic device, CMC-Ph microgels were prepared with the radius from 100 to $500 \mu \mathrm{m}$ via adjusting the flow rates of the disperse phase and the continuous phase, respectively. The chondrocytic cell line ATDC5 was encapsulated in the CMC-Ph microgels. The cell-laden microgels were cultured for up to 40 days, illustrating the biocompatibility of $\mathrm{CMC}-\mathrm{Ph}$ and the microfluidic approach through the enzymatic crosslinking reaction primarily. CMC-Ph showed a great promise to encapsulate the cells for further fabrication of the injectable scaffolds.
\end{abstract}

Keywords: biocompatible polymers, polymer synthesis, polymer gels, carboxymethyl cellulose, microfluidic

\section{Introduction}

Osteoarthritis, characterized by progressively degeneration or loss of articular cartilage, is the most common form of arthritis. Tissue engineering has shown great promise as a strategy to develop biological substitutes to restore, replace or regenerate the defective tissue [1]. Scaffolds made of polymeric biomaterials offer support for cell attachment, proliferation and differentiation [2,3]. Encapsulation of living cells within a semi-permeable membrane is a simple one-step procedure with characteristics of homogenous cell distribution and excellent cell viability $[4,5]$. Its unique self-assembled capability makes it suitable for injectable scaffolds for in situ tissue regeneration. Recent advances in microfluid designs have brought the field of microfluidics to the forefront of the preparation of microor nano-gels for cell encapsulation [6-8].

Many naturally derived biomaterials have been used for encapsulation, such as sodium alginate [9] and agarose [10]. However, these biomaterials have limited ability to support cell attachment, growth and differentiation, resulting in low cell viability and growth [11]. Carboxymethyl cellulose (CMC) is a water-soluble, biodegradable and biocompatible derivative of cellulose. Its hydrophilic carboxylic or hydroxyl groups serve as active sites for preparing CMC gels. Physical-crosslinking CMC gels via

\footnotetext{
${ }^{*}$ Corresponding author, e-mail: imwugang@scut.edu.cn

(C) BME-PT
} 
supermolecular [12] and ionic [13] interaction are simple to be produced, but usually questioned by their reversibility.

Chemical-crosslinking provides CMC gels a more stable three-dimensional network. For example, divinyl sulfone [14], epichlorohydrin [15], aldehydes [16, 17], fumaric acid [18] and citric acid [19] have been used as crosslinkers to form CMC and CMC composite gels. Monomers with double bond, such as $N$-isopropyl acrylamide [20] and partially neutralized acrylic acid/rectorite [21], have been initiated by ammonium persulfate and coupled onto CMC backbones via methylene bisacrylamide (crosslinker). These chemical crosslinkers are limited for the applications in biomedical or pharmaceutical areas because of their toxicity or the stimulatory reaction to the encapsulated bioactive molecules or live cells. A bio-based carbodiimide crosslinker has been used to prepare chitosan/CMC microgels [22], indicating a very low efficiency of crosslinking reaction. Another synthetic route is to form $\mathrm{CMC}$ gels via functional groups of both components without any crosslinker, for example, hydrazide-functionalized CMC/aldehyde-functionalized dextran, suggested by Kesselman et al. [23]. They have introduced the two reactive streams into a continuous oil solution simultaneously through two separate inlets of a microfluidics device. However, the premixing of the reactive streams before the formation of droplets often resulted in the blockage of small opening of the microfluidics.

Enzymatic reaction has been extensively studied owing to its low toxicity, mild reaction, stereochemistry, and high reaction velocity, high enantio-, regio- and chemo-selectivity [24]. Horseradish peroxidise/hydrogen peroxide $\left(\mathrm{HRP} / \mathrm{H}_{2} \mathrm{O}_{2}\right)$ is a common enzymatic system, where peroxidases (oxidoreductases) catalyzes the oxidation of donors using $\mathrm{H}_{2} \mathrm{O}_{2}$, resulting in polyphenols linked at the aromatic ring by $\mathrm{C}-\mathrm{C}$ and $\mathrm{C}-\mathrm{O}$ coupling of phenols [25]. DeVolder et al. [26] have prepared hydrogels of alginate grafted with pyrrole groups through a HRP-activated crosslinking reaction for drug release system. We designed a special microfluidic device to prepare monodisperse CMC-based microdroplets [27]. In this work, we synthesized 4-hydroxybenzylamine modified $\mathrm{CMC}$ (CMC-Ph) with different molecular weight and prepared CMC-Ph microgels through an enzymatic reaction. The properties of
$\mathrm{CMC}-\mathrm{Ph}$ that influenced the formation of microgels were studied. Moreover, cells were encapsulated in CMC-Ph microgels to study the biocompatibility of $\mathrm{CMC}-\mathrm{Ph}$ and the microfluidic approach through the enzymatic crosslinking reaction.

\section{Experimental \\ 2.1. Materials}

1-Ethyl-3-(3-dimethylaminopropyl)carbodiimide hydrochloride (EDC), $\mathrm{N}$-hydroxysulfosuccinimide (NHS), HRP (250 units/mg), lecithin, 4-hydroxybenzylamine, 1-hydroxybenzotriazole hydrate (HOBT) and 2-(4-morpholino)ethanesulfonic acid (MES) were obtained from Qiyun Biotech (China). Aqueous $\mathrm{H}_{2} \mathrm{O}_{2}(30 \%$, w/w) and liquid paraffin were purchased from Dalu Chemical Reagent (China). All reagents were of analytical grade and used as received.

$\mathrm{CMC}$ with $M_{\mathrm{w}}$ of $1.0 \times 10^{5}\left(\mathrm{CMC}_{10}\right), 2.0 \times 10^{5}\left(\mathrm{CMC}_{20}\right)$ and $3.0 \times 10^{5}\left(\mathrm{CMC}_{30}\right)$ were purchased from Jingchun Chemical Reagent (China). CMC-Ph was synthesized according to our previous study [27]: Briefly, $\mathrm{CMC}$ and 4-hydroxybenzylamine were dissolved in MES buffer (50 mM, pH 6.0) at 1.0 and $0.6 \%$, respectively. NHS, HOBt and EDC were added at a weight ratio of 1:0.26:0.68:0.70 (CMC:NHS:HOBt: EDC). The solution was magnetic stirred for 24 hours and dialyzed against deionized water using an ultrafiltration membrane (molecular weight cutoff $=3500 \mathrm{Da})$ at $25^{\circ} \mathrm{C}$ for 4 days. The resultant polymer solution was enriched by a rotary evaporator $(100 \mathrm{rpm})$ at $50^{\circ} \mathrm{C}$ and lyophilized.

\subsection{Preparation of CMC-Ph microgels}

A co-flowing microfluidic device with an inner diameter of $260 \mu \mathrm{m}$ and an outer diameter of $510 \mu \mathrm{m}$ was used for preparing $\mathrm{CMC}-\mathrm{Ph}$ microparticles. The continuous liquid paraffin phase was prepared as follows: In brief, $250 \mathrm{~mL}$ of liquid paraffin containing $1.25 \mathrm{~mL} \mathrm{H}_{2} \mathrm{O}_{2}$ was magnetically stirred for 12 hours at $25^{\circ} \mathrm{C}$ and centrifuged at $2000 \mathrm{rpm}$ for 10 minutes. Lecithin was dissolved at $3.0 \%(\mathrm{w} / \mathrm{v})$ into the upper liquid paraffin containing $\mathrm{H}_{2} \mathrm{O}_{2}$. $\mathrm{CMC}-\mathrm{Ph}$ aqueous solution containing HRP as the dispersed phase was injected into the microfluidic device using a micro-syringe pump (Baoding Longer TS-1B/W0109-1B, China), and the continuous phase was injected into an inlet in a perpendicular direction. The particles flew along the channel and finally collected. 


\subsection{Preparation of cell-laden CMC-Ph microgels}

The lyophilized CMC-Ph was sterilized by exposure to epoxyethane vapor. CMC-Ph $(\sim 0.2 \mathrm{~g})$ was dissolved in $4 \mathrm{~mL}$ of Dulbecco's modified Eagle medium (DMEM, Hyclone, USA). HRP was then dissolved at $1 \mathrm{mg} / \mathrm{mL}$ in DMEM, and the solution was kept at $37^{\circ} \mathrm{C}$. The chondrocytic cell line ATDC5 (Sigma, USA) of sixth passage was trypsinized at a density of $1 \times 10^{7}$ cells $/ \mathrm{mL}$. $1 \mathrm{~mL}$ of cell suspension was added into the CMC-Ph solution containing HRP, which injected as the dispersed phase at a rate of $50 \mu \mathrm{L} / \mathrm{min}$. The continuous liquid paraffin phase was injected at a rate of $10 \mathrm{~mL} / \mathrm{min}$. The resulted microgels were collected and centrifuged at $2000 \mathrm{rpm}$ for $5 \mathrm{~min}$. Phosphate buffer saline (PBS, $\mathrm{pH}=7.4$, Gibco, USA) was added to the tube, followed by centrifuging at $2000 \mathrm{rpm}$ for $5 \mathrm{~min}$ twice. The collected cell-laden CMC-Ph microgels were removed into 6-well cell culture dishes (Corning, USA). Cells enclosed in microgels were incubated in DMEM supplemented with $10 \%(\mathrm{v} / \mathrm{v})$ fetal bovine serum (FBS, Gibco, USA) in a humidified atmosphere at $37^{\circ} \mathrm{C}$ under $5 \% \mathrm{CO}_{2}$. The medium was exchanged for fresh medium every 2 days, and a new cell culture dish was replaced every 4 days till cellculturing for 40 days. The morphology of the cellladen $\mathrm{CMC}-\mathrm{Ph}$ microgels was evaluated under an inverted light microscope (Nikon ECLIPSE TS100, Japan).

\subsection{Characterization}

A Bruker (Germany) Vertex 70 Fourier transform infrared spectrometry (FTIR) was used to obtain infrared analyses of 4-hydroxybenzylamine, CMC and $\mathrm{CMC}-\mathrm{Ph}$ using $\mathrm{KBr}$ pellet method. The spectra comprised 64 scans at a resolution of $1 \mathrm{~cm}^{-1}$ in $4000 \sim 400 \mathrm{~cm}^{-1}$ spectral range.

${ }^{1} \mathrm{H}$ nuclear magnetic resonance (NMR, Drx-400 Bruker, Germany) spectra were achieved at $400 \mathrm{MHz}$ using deuterated water $\left(\mathrm{D}_{2} \mathrm{O}\right)$ as solvent in the presence of tetramethylsilane as an internal standard.

Graft density of phenols in CMC-Ph was calculated by measuring the absorbance at $275 \mathrm{~nm}$ of CMC-Ph solutions using a Thermo (USA) Evolution 300 UVVIS spectrometer. The absorbance being measured was compared with a 4-hydroxybenzylamine standard curve. The graft density of phenols then calculated from the ratio of phenols to 100 repeat units of CMC. The data was the mean of five samples.
Molecular weight and polydispersity index (PDI) of $\mathrm{CMC}$ and $\mathrm{CMC}-\mathrm{Ph}$ were determined by a Water (USA) 515-410 gel permeation chromatography (GPC). Weight-average $\left(M_{\mathrm{w}}\right)$ and number-average $\left(M_{\mathrm{n}}\right)$ molecular weight were expressed with respect to polyethyleneglycol standards.

Rheological behavior of CMC-Ph solutions with different concentrations was measured using a TA (USA) ARES/RFS rotational viscometer at 16 and $30^{\circ} \mathrm{C}$, respectively. The solutions were prepared by mass using a XS105DU balance (Mettler Toledo, Switzerland) with a precision of $10^{-5} \mathrm{~g}$. The employed shear rate varied from 0.01 to $250 \mathrm{~s}^{-1}$, and viscosity and stress were identified.

Stereomicroscope images of the microdroplets in the liquid paraffin were obtained with a SMZ-DM200 stereomicroscope (Optec, China) with a digital CCD camera to estimate the size in number-average diameters and coefficients of variation $(\mathrm{CV}$, defined as the ratio of standard deviation to the mean) by analyzing images of 100 particles in liquid paraffin phase.

\section{Results and discussion}

\subsection{CMC-Ph}

\subsubsection{FTIR spectrum}

In Figure 1a, the absorption bands at 1450, 1501, 1561 and $1611 \mathrm{~cm}^{-1}$ were ascribed to the benzene skeleton vibration. The peaks at 842, 1261 and $1386 \mathrm{~cm}^{-1}$ were attributed to the $\mathrm{C}-\mathrm{H}$ out-of-plane bending vibration of benzene ring, $\mathrm{C}-\mathrm{O}$ stretching vibration and $\mathrm{O}-\mathrm{H}$ in-plane bending vibration of phenol, respectively. The absorption peak at $1642 \mathrm{~cm}^{-1}$ was associated to $\mathrm{N}-\mathrm{H}$ scissoring vibration of free amine. The broad association peak at $3423 \mathrm{~cm}^{-1}$ would be the stretching vibration of $\mathrm{C}-\mathrm{H}$, $\mathrm{O}-\mathrm{H}$ and $\mathrm{N}-\mathrm{H}$, in which a hydrogen bond formed between a hydrogen atom and $\mathrm{O}-\mathrm{H}$ group or $\mathrm{N}-\mathrm{H}$ group. In FTIR spectrum of CMC-Ph (Figure 1b, curve (2)), the absorption bands at 1045, 1323 and $1415 \mathrm{~cm}^{-1}$ were attributed to the $-\mathrm{C}=\mathrm{O}$ stretching vibration, in-plane bending vibration of $\mathrm{O}-\mathrm{H}$ and $\mathrm{C}-\mathrm{H}$ scissoring vibration of methylene of CMC, respectively (Figure 1b, curve (1)). The characteristic absorption bands of 4-hydroxybenzylamine were traced, including the $\mathrm{C}-\mathrm{H}$ out-of-plane bending vibration of benzene ring $\left(827 \mathrm{~cm}^{-1}\right), \mathrm{C}-\mathrm{O}$ strong stretching vibration of phenol $\left(1257 \mathrm{~cm}^{-1}\right)$, benzene skeleton vibration $\left(1504\right.$ and $\left.1456 \mathrm{~cm}^{-1}\right)$ and $\mathrm{N}-\mathrm{H}$ scissoring vibration of free amine $\left(1644 \mathrm{~cm}^{-1}\right)$. The 

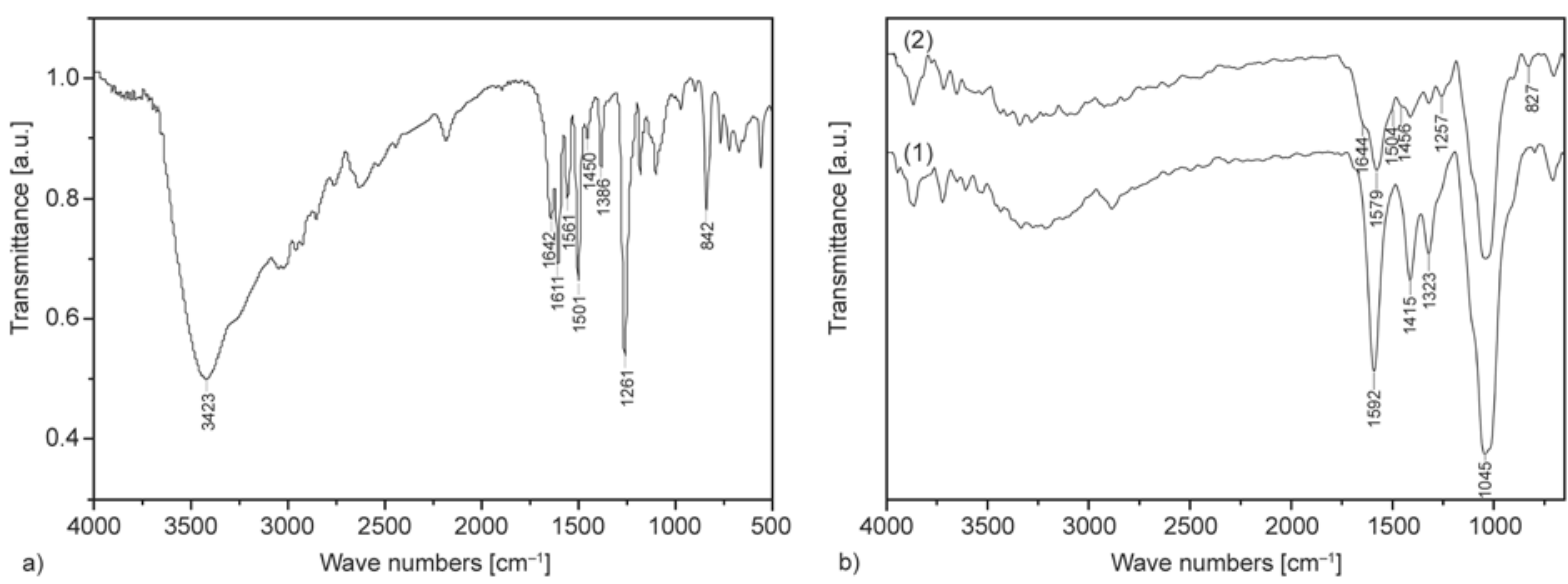

Figure 1. FTIR spectra of 4-hydroxybenzylamine (a), CMC (b-(1)) and CMC-Ph (b-(2))

band with a peak at $1579 \mathrm{~cm}^{-1}$ was the IR absorption of the -O- stretching vibration of CMC $\left(1592 \mathrm{~cm}^{-1}\right.$, Figure $1 \mathrm{~b}$, curve (1)) and the benzene skeleton vibration $\left(1561\right.$ and $\left.1611 \mathrm{~cm}^{-1}\right)$.

\subsection{2. ${ }^{1} \mathrm{H}$ NMR spectra}

Figure 2 illustrates ${ }^{1} \mathrm{H}$ NMR spectra along with schematics of their chemical structures, on which proton assignments are indicated. 4-Hydroxybenzylamine (Figure 2a) showed chemical shifts $(\delta)$ at 6.60 and $7.06 \mathrm{ppm}$ of aromatic protons (a) and (b), respectively, and at $3.81 \mathrm{ppm}$ of aliphatic protons (c). The spectra of CMC (Figure 2b) and CMC-Ph (Figure 2c) showed $\delta$ of anomeric protons at 4.15 and $4.42 \mathrm{ppm}$, and sugar ring protons between 3.11 and $3.99 \mathrm{ppm}$ for both macromolecules [28]. The signals at 7.21 and $6.84 \mathrm{ppm}$ of CMC-Ph spectrum were attributed to the aromatic protons of 4-hydroxybenzylamine being grafted with $\mathrm{CMC}(\mathrm{CMC}-\mathrm{g}-\mathrm{Ph}$, $1 \mathrm{a}$ and $1 \mathrm{~b}$ ). The strong inductive effect being caused by the neighboring carbonyl groups decreased the electron density of the benzene ring, so that $\delta$ of aromatic protons decreased compared with those of 4-hydroxybenzylamine (Figure 2a, (a) and (b)). The signals at 1.79 2.02 ppm (2a), 0.96 1.19 ppm (2b) and $2.75 \mathrm{ppm}(2 \mathrm{c})$ were ascribed to the byproduct being formed between CMC and EDC (CMC-EDC). EDC and phenolic groups of 4-hydroxybenzylamine reacted to form CMC-g-Ph-EDC, resulting in a change in proton shift of the aromatic protons at 7.51 and $7.35 \mathrm{ppm}$ (3a and $3 b)$ [29].

\subsubsection{Graft density of phenols}

The CMC-Ph aqueous solution showed a specific absorbance with a peak at $275 \mathrm{~nm}$ of 4-hydroxy- benzylamine. We also tested the dialysis solution at four days, the UV absorption was not detected, so that the UV absorption of the CMC-Ph solution would be ascribed to the grafted 4-hydroxybenzylamine. Based on the standard curve, the amount of the grafted 4-hydroxybenzylamine per 100 units of CMC (grafting density) was calculated (Table 1). It fell in the range of 17 23, and increased as $M_{\mathrm{w}}$ of $\mathrm{CMC}$ increased. Usually, the flexibility of polymer increased with the increasing molecular weight, so that CMC with higher $M_{\mathrm{w}}$ or $M_{\mathrm{n}}$ was favorable to collide effectively with small molecules via changing conformation, leading to a higher reaction probability of CMC with 4-hydroxybenzylamine.

\subsubsection{Molecular weight}

The molecular weight and the polydispersity (PI) of the molecular weight were also shown in Table 1. $M_{\mathrm{w}}, M_{\mathrm{n}}$ and PI of CMC-Ph were higher than those of CMC. The difference of molecular weight between $\mathrm{CMC}$ and $\mathrm{CMC}-\mathrm{Ph}$ increased as the molecular weight of CMC increased, perhaps owing to a slight crosslinking between hydroxyl groups of 4-hydroxybenzylamine and carboxyl groups of CMC under EDC/ NHS reactive system.

Table 1. Grafting density and molecular weight of CMC-Ph

\begin{tabular}{|c|c|c|c|c|}
\hline & $\begin{array}{c}\text { Grafting } \\
\text { density }\end{array}$ & $\begin{array}{c}M_{\mathrm{n}} \\
\left(\times 10^{-4}\right)\end{array}$ & $\begin{array}{c}M_{\mathrm{w}} \\
\left(\times 10^{-4}\right)\end{array}$ & Polydispersity \\
\hline $\mathrm{CMC}_{10}$ & 0 & 4.47 & 9.86 & 2.2 \\
\hline $\mathrm{CMC}_{20}$ & 0 & 6.20 & 24.53 & 4.0 \\
\hline $\mathrm{CMC}_{30}$ & 0 & 10.20 & 31.52 & 3.1 \\
\hline $\mathrm{CMC}_{10}-\mathrm{Ph}$ & 17.4 & 4.44 & 17.43 & 3.9 \\
\hline $\mathrm{CMC}_{20}-\mathrm{Ph}$ & 17.8 & 9.42 & 48.08 & 5.1 \\
\hline $\mathrm{CMC}_{30}-\mathrm{Ph}$ & 22.5 & 17.36 & 87.50 & 5.0 \\
\hline
\end{tabular}




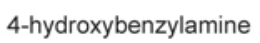

a)

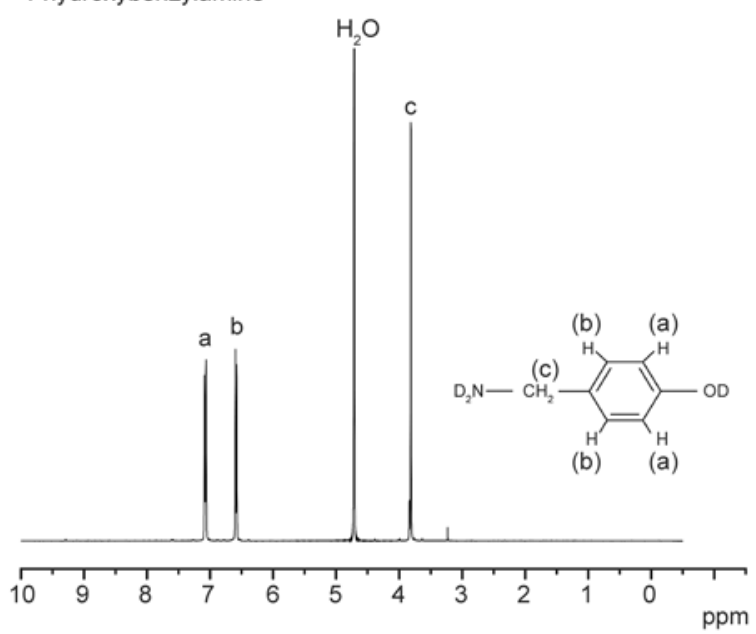

b)

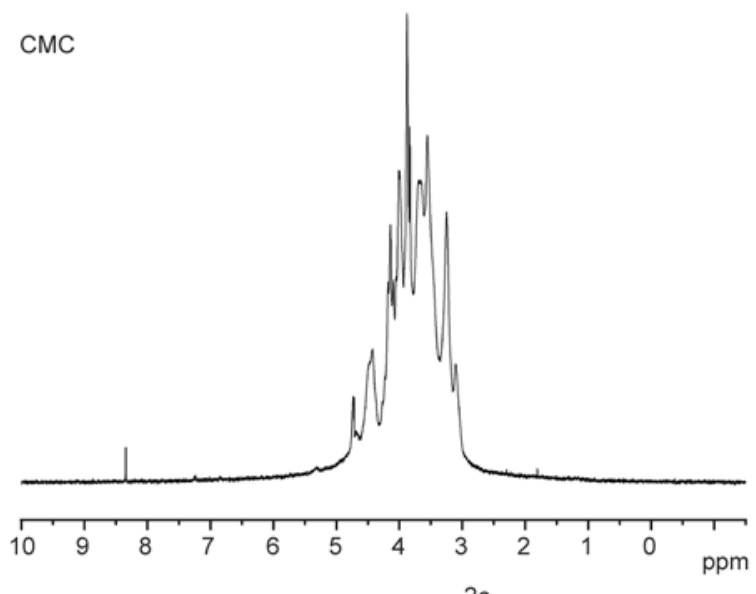

c)

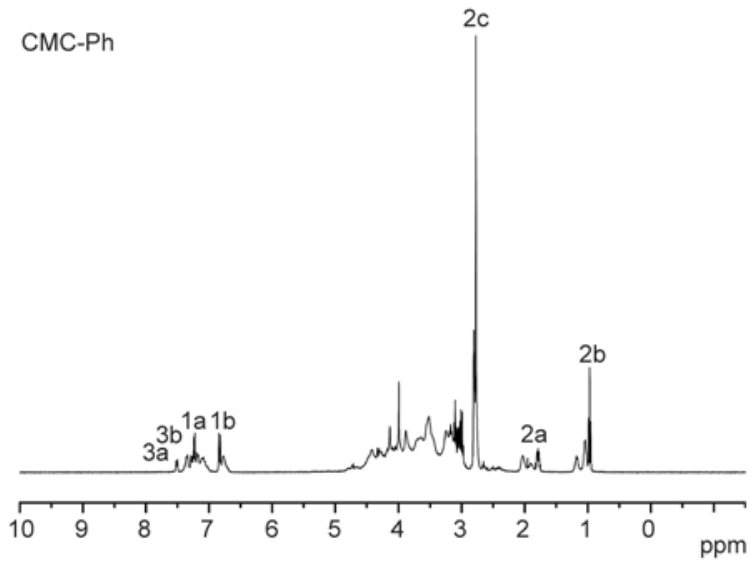

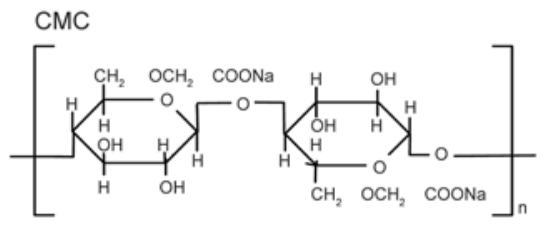

CMC-g-Ph<smiles></smiles>

CMC-EDC<smiles>CCCCCN(C(=O)NCCCN(C)C)C(=O)c1ccccc1</smiles>

CMC-g-Ph-EDC

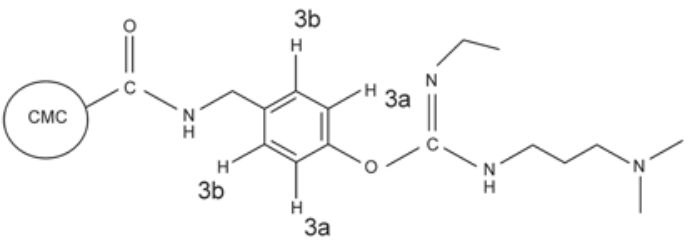

Figure 2. ${ }^{1} \mathrm{H}$ NMR spectra of 4-hydroxybenzylamine (a), CMC (b) and CMC-Ph (c) with protons assigned

\subsubsection{Viscosity}

Rheological behavior of the CMC-Ph solution with the different molecular weight has been determined by analyzing the influence of shear rate on viscosity. Flow curve was a straight line passing through the origin, and the stress increased lineally with the shear rate at $30^{\circ} \mathrm{C}$, respectively (Figure $3\left(\mathrm{a}_{2}\right),\left(\mathrm{b}_{2}\right)$, $\left(c_{2}\right)$. An increase in the molecular weight produced an increase in the viscosity (Figure 3). For example, the viscosity was $5.4,14.8$ and $25.5 \mathrm{mPa} \cdot \mathrm{s}$, respectively for $\mathrm{CMC}_{10}-\mathrm{Ph}, \mathrm{CMC}_{20}-\mathrm{Ph}$ and $\mathrm{CMC}_{30}-\mathrm{Ph}$ at $30^{\circ} \mathrm{C}$. As the molecular weight of $\mathrm{CMC}-\mathrm{Ph}$ increased, the intermolecular volume decreased and thus the molecular interaction of $\mathrm{CMC}-\mathrm{Ph}$ increased. The CMC-Ph with high molecular weight possessed low ability to rearrange and move past each other, so 


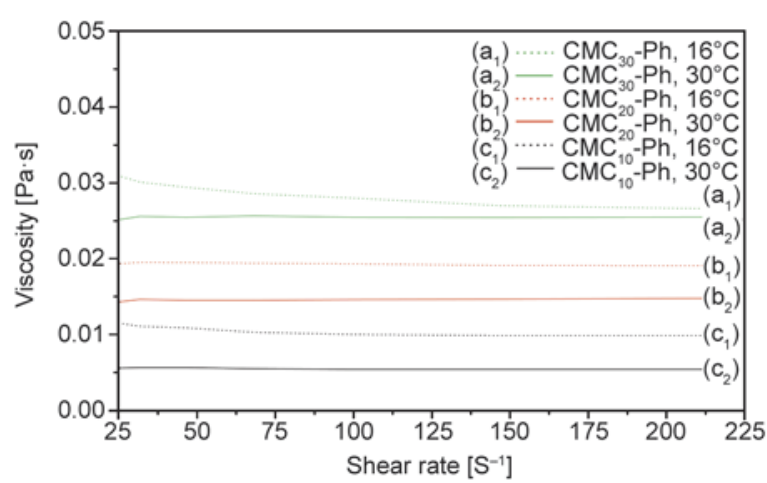

Figure 3. Viscosity of $1.0 \% \mathrm{CMC}-\mathrm{Ph}$ solution being measured at $16^{\circ} \mathrm{C}$ : $\left(\mathrm{a}_{1}\right) \mathrm{CMC}_{30}-\mathrm{Ph} ;\left(\mathrm{b}_{1}\right) \mathrm{CMC}_{20}-\mathrm{Ph}$; (c $\left.\mathrm{c}_{1}\right) \mathrm{CMC}_{10}-\mathrm{Ph}$, and at $30^{\circ} \mathrm{C}:\left(\mathrm{a}_{2}\right) \mathrm{CMC}_{30}-\mathrm{Ph}$; $\left(\mathrm{b}_{2}\right) \mathrm{CMC}_{20}-\mathrm{Ph} ;\left(\mathrm{c}_{2}\right) \mathrm{CMC}_{10}-\mathrm{Ph}$

that the internal resistance to flow increased. Therefore, the viscosity increased with the increasing molecular weight of CMC-Ph.

At $16^{\circ} \mathrm{C}$, the viscosity of $\mathrm{CMC}_{30}$-Ph decreased significantly with the increasing shear rate. When the shear rate was $215 \mathrm{~s}^{-1}$, the viscosity was 9.9, 19.1 and $26.6 \mathrm{mPa} \cdot \mathrm{s}$, respectively for $\mathrm{CMC}_{10}-\mathrm{Ph}, \mathrm{CMC}_{20}-\mathrm{Ph}$ and $\mathrm{CMC}_{30}-\mathrm{Ph}$. In general, an increase in temperature allows quicker molecules motion and thus less energy is needed to flow CMC-Ph solution, resulting in a decrease in the viscosity. When the shear rate was $215 \mathrm{~s}^{-1}$, the difference between viscosity measuring at 16 and $30^{\circ} \mathrm{C}$ was $4.45,4.31$ and $1.08 \mathrm{mPa} \cdot \mathrm{s}$ for $\mathrm{CMC}_{10}-\mathrm{Ph}, \mathrm{CMC}_{20}-\mathrm{Ph}$ and $\mathrm{CMC}_{30}-\mathrm{Ph}$, respectively. The less difference of $\mathrm{CMC}_{30}-\mathrm{Ph}$ was perhaps owing to the decreasing viscosity as the shear rate increased. As the shear rate was $215 \mathrm{~s}^{-1}$, the viscosity ratio of $\mathrm{CMC}_{30}-\mathrm{Ph}$ to $\mathrm{CMC}_{10}-\mathrm{Ph}$ at $16^{\circ} \mathrm{C}$ was 2.7 , which reached 4.7 when temperature went up to $30^{\circ} \mathrm{C}$.

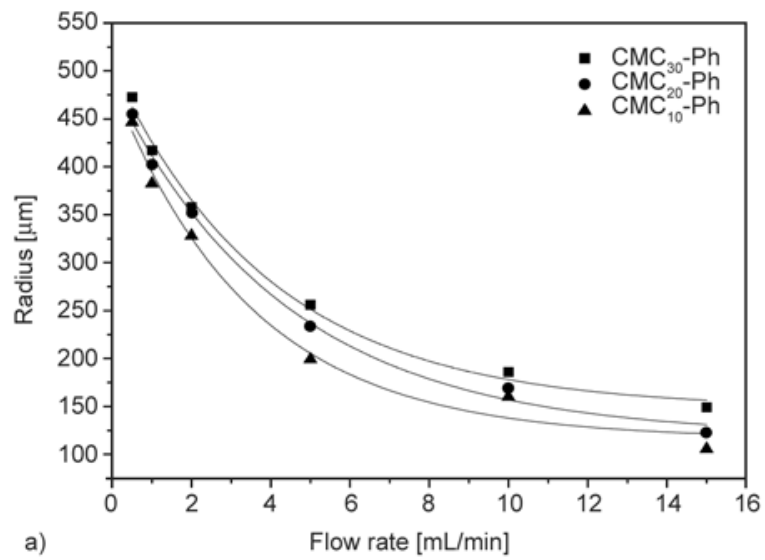

\subsection{CMC-Ph microgels}

Prior to the microfluidic preparation of CMC-Ph microgels, we examined the gelation of the disperse fluid as the presence of $\mathrm{H}_{2} \mathrm{O}_{2}$. The CMC-Ph gels were formed after a contact time of $1 \mathrm{~min}$. In the microfluidic device, the viscous disperse fluid was extruded into the immiscible continuous liquid flowing in the same direction. The disperse fluid flowed and snapped off at the orifice. $\mathrm{H}_{2} \mathrm{O}_{2}$ in the continuous liquid surrounded the $\mathrm{CMC}-\mathrm{Ph}$ droplets containing HRP. Thereafter, diffusion of $\mathrm{H}_{2} \mathrm{O}_{2}$ from the continuous fluid to the disperse phase triggered the gelation reaction to bind the phenols groups.

Because $\mathrm{H}_{2} \mathrm{O}_{2}$ was separated from HRP, the enzymatic reaction cannot occur before the droplets formation, thus avoiding the blockage of the inner opening. The concentration of $\mathrm{H}_{2} \mathrm{O}_{2}$ in the continuous phase $(0.82 \mathrm{mmol} / \mathrm{L})$ would not bring severe harmful effect on the encapsulated contents, but it was enough for gelation of the microdroplets. The $\mathrm{CMC}-\mathrm{Ph}$ microgels were intact while immersed in DMEM for 40 days. This diffusion-controlled crosslinking was very important for improving the integrity and encapsulation efficiency of microparticles.

We prepared the CMC-Ph microdroplets with different molecular weight while using the $1 \% \mathrm{CMC}$ $\mathrm{Ph}$ containing HRP $(1 \mathrm{mg} / \mathrm{mL})$. As the flow rate of the disperse phase $\left(Q_{\mathrm{d}}\right)$ was fixed at $10 \mu \mathrm{L} / \mathrm{min}$, the effect of the flow rate of the continuous phase $\left(Q_{\mathrm{c}}\right)$ on the radius of microdroplets was shown in Figure 4a. The increased flow rate of the continuous phase produced a stronger shear force, thus resulted in a decreasing radius of the $\mathrm{CMC}-\mathrm{Ph}$ microdroplets.

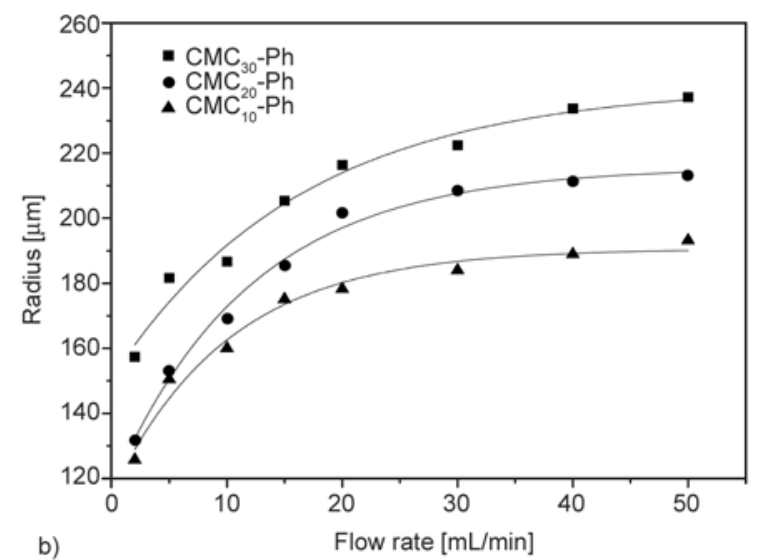

Figure 4. Dependence of flow rates on the size of the microdroplets obtained by using $1.0 \% \mathrm{CMC}_{10}-\mathrm{Ph}$ (triangle), $\mathrm{CMC}_{20^{-}}$ $\mathrm{Ph}$ (circle) and $\mathrm{CMC}_{30} \mathrm{Ph}$ (square): (a) effect of $Q_{\mathrm{c}}$ on the radius of microdroplets at a constant $Q_{\mathrm{d}}(10 \mu \mathrm{L} / \mathrm{min})$; (b) effect of $Q_{\mathrm{d}}$ on the radius of microdroplets at a fixed $Q_{\mathrm{c}}(10 \mathrm{~mL} / \mathrm{min})$ 
When using a fixed $Q_{\mathrm{c}}(10 \mathrm{~mL} / \mathrm{min})$, the radius of the $\mathrm{CMC}-\mathrm{Ph}$ microdroplets increased with an increasing flow rate of the disperse fluid (Figure 4b). In general, the $\mathrm{CMC}-\mathrm{Ph}$ solution with higher molecular weight produced larger microdroplets due to higher viscosity.

\subsection{Cell-laden CMC-Ph microgels}

The injectable microsphere scaffolds should support cells adhesion, migration, and proliferation, and more important, maintain the differentiated phenotype of the cells within the scaffold. The cellladen microgels would facilitate gas exchange, nutrient diffusion, and waste metabolism. ATDC5 is a prechondrogenic stem cell line, and reproduces the differentiation stages of chondrocytes during endochondral bone formation [30]. The ATDC5laden microgels being cultured up to 40 days were shown in Figure 5. The microgels presented round morphology that was very important for mechanical stability under the compressive forces in the body. The living cells (light dots) were distributed separately in the microgels (Figure 5a). Some of the cellladen microgels broke with the damaged border. The microgel did not maintain the round morphology any more (Figure $5 b$ ). Some of the cells released from the broken microgels and can stick to the cell culture dishes at 40 days of culturing (Figure 5c), showing high viability.

\section{Conclusions}

4-Hydroxybenzylamine modified CMC with different molecular weight was synthesized through EDC/ NHS coupling agents. Uniform CMC-Ph microparticles were obtained in the co-flowing microfluidic devices. The radius was tuned in the range of $(100$ 500) $\mu \mathrm{m}$ by changing the flow rates of the disperse phase and the continuous phase, respectively. The cells encapsulated in $\mathrm{CMC}-\mathrm{Ph}$ microgels were still living at 40 days of culturing. The microfluidic approach to the preparation of the cell-laden microgels will provide a potential method of fabricating scaffolds for tissue engineering, especially in the defect with an irregular-shape and/or a minimally invasive approach. The CMC-Ph microgels with the different molecular weight along with the different encapsulating content may also been used to prepare the injectable microsphere scaffolds, having a

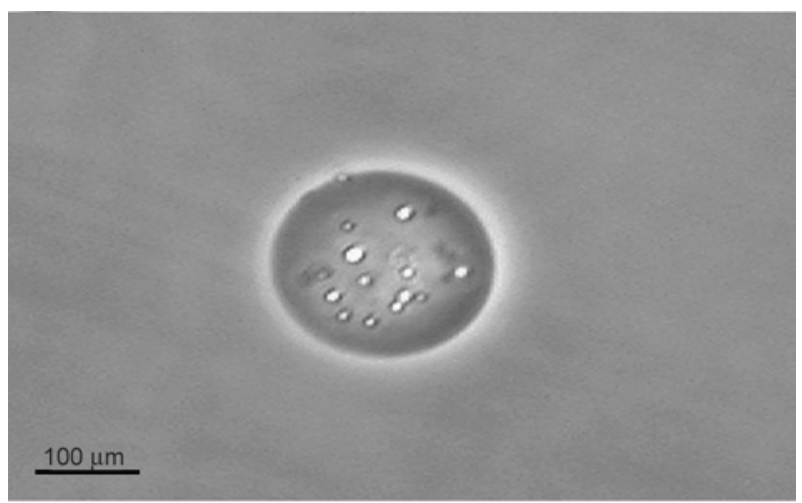

a)

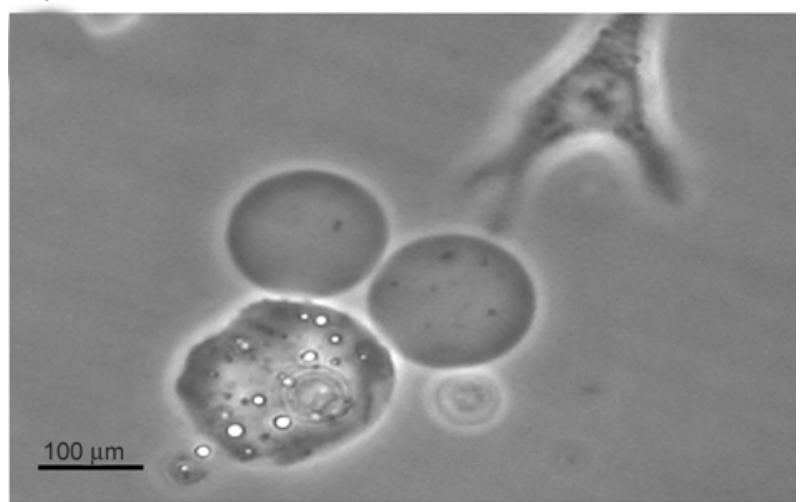

b)

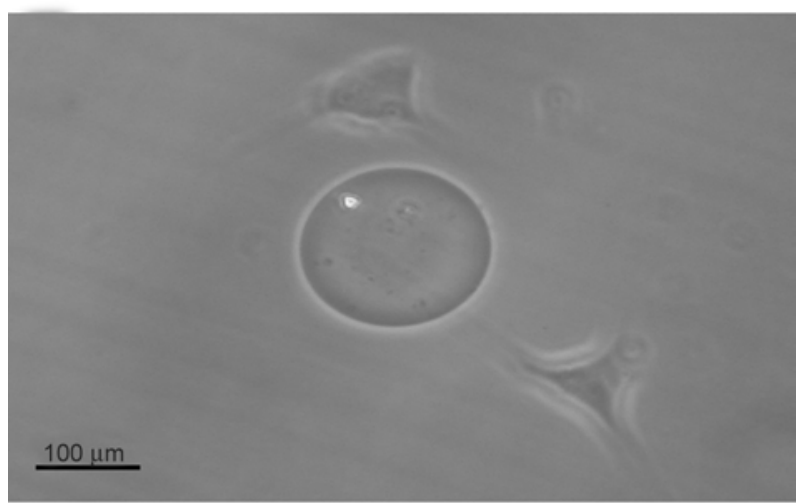

c)

Figure 5. Photographs of the cell-laden microgels up to 40 days of culturing: (a) living cells distributed separately at 40 days; (b) broken cell-laden microgels at 5 days; (c) cells from the broken microgels sticking to the dishes at 40 days

gradient mechanical property, a gradient encapsulating content, and a gradient releasing property.

\section{Acknowledgements}

This study was financially supported by the Basic Research Project of China (2012CB619105), the National Natural Science Foundation of China (51072056, 51173053), Guangdong Natural Science Foundation (9451063201003024), Guangdong Provincial Program for Excellent Talents in Universities, and Key Laboratory of Biomaterials of Guangdong Higher Education Institutes of Jinan University. 


\section{References}

[1] Langer R., Vacanti J. P.: Tissue engineering. Science, 260, 920-926 (1993).

DOI: $10.1126 /$ science. 8493529

[2] Hutmacher D. W.: Scaffolds in tissue engineering bone and cartilage. Biomaterials, 21, 2529-2543 (2000). DOI: 10.1016/S0142-9612(00)00121-6

[3] Ke Y., Wu G., Wang Y. J.: PHBV/PAM scaffolds with local oriented structure through UV polymerization for tissue engineering. BioMed Research International, 2014, 157987/1-157987/9 (2014).

DOI: $10.1155 / 2014 / 157987$

[4] Lanza R. P., Hayes J. L., Chick W. L.: Encapsulated cell technology. Nature Biotechnology, 14, 1107-1111 (1996).

DOI: $10.1038 /$ nbt0996-1107

[5] Orive G., Hernández R. M., Gascón A. R., Calafiore R., Chang T. M. S., De Vos P., Hortelano G., Hunkeler D., Lacík I., Shapiro A. M. J., Pedraz J. L.: Cell encapsulation: Promise and progress. Nature Medicine, 9, 104107 (2003).

DOI: $10.1038 / \mathrm{nm} 0103-104$

[6] Dendukuri D., Doyle P. S.: The synthesis and assembly of polymeric microparticles using microfluidics. Advanced Materials, 21, 4071-4086 (2009).

DOI: $10.1002 /$ adma.200803386

[7] Lazarus L. L., Riche C. T., Marin B. C., Gupta M., Malmstadt N., Brutchey R. L.: Two-phase microfluidic droplet flows of ionic liquids for the synthesis of gold and silver nanoparticles. ACS Applied Materials and Interfaces, 4, 3077-3083 (2012).

DOI: $10.1021 / \mathrm{am} 3004413$

[8] Ke Y.: Microfluidic-assisted fabrication of nanoparticles for nanomedicine application. Recent Patents on Nanomedicine, 1, 109-122 (2011).

DOI: $10.2174 / 1877912311101020109$

[9] Sakai S., Kawakami K.: Both ionically and enzymatically crosslinkable alginate-tyramine conjugate as materials for cell encapsulation. Journal of Biomedical Materials Research Part A, 85, 345-351 (2008).

DOI: 10.1002/jbm.a.31299

[10] Batorsky A., Liao J., Lund A. W., Plopper G. E., Stegemann J. P.: Encapsulation of adult human mesenchymal stem cells within collagen-agarose microenvironments. Biotechnology and Bioengineering, 92, 492500 (2005).

DOI: $10.1002 /$ bit.20614

[11] Zimmermann H., Hillgärtner M., Manz B., Feilen P., Brunnenmeier F., Leinfelder U., Weber M., Cramer H., Schneider S., Hendrich C., Volke F., Zimmermann U.: Fabrication of homogeneously cross-linked, functional alginate microcapsules validated by NMR-, CLSM- and AFM-imaging. Biomaterials, 24, 2083-2096 (2003). DOI: $\underline{10.1016 / \mathrm{S} 0142-9612(02) 00639-7}$
[12] Liu H., Huang S., Li X., Zhang L., Tan Y., Wei C., Lv J.: Facile fabrication of novel polyhedral oligomeric silsesquioxane/carboxymethyl cellulose hybrid hydrogel based on supermolecular interactions. Materials Letters, 90, 142-144 (2013). DOI: $10.1016 /$ j.matlet.2012.09.030

[13] Zhang H., Tumarkin E., Peerani R., Nie Z. H., Sullan R. M. A., Walker G. C., Kumacheva E.: Microfluidic production of biopolymer microcapsules with controlled morphology. Journal of the American Chemical Society, 128, 12205-12210 (2006). DOI: $10.1021 / \mathrm{ja} 0635682$

[14] Butun S., Ince F. G., Erdugan H., Sahiner N.: One-step fabrication of biocompatible carboxymethyl cellulose polymeric particles for drug delivery systems. Carbohydrate Polymers, 86, 636-643 (2011). DOI: $10.1016 /$ j.carbpol.2011.05.001

[15] Chang C., He M., Zhou J., Zhang L.: Swelling behaviors of $\mathrm{pH}$ - and salt-responsive cellulose-based hydrogels. Macromolecules, 44, 1642-1648 (2012). DOI: $10.1021 / \mathrm{ma102801 \textrm {f }}$

[16] Rao K. M., Mallikarjuna B., Rao K. S. V. K., Prabhakar M. N., Rao K. C., Subha M. C. S.: Preparation and characterization of $\mathrm{pH}$ sensitive poly(vinyl alcohol)/sodium carboxymethyl cellulose IPN microspheres for in vitro release studies of an anti-cancer drug. Polymer Bulletin, 68, 1905-1919 (2012). DOI: $10.1007 / \mathrm{s} 00289-011-0675-9$

[17] Patenaude M., Hoare T.: Injectable, mixed naturalsynthetic polymer hydrogels with modular properties. Biomacromolecules, 13, 369-378 (2012).

DOI: $10.1021 / \mathrm{bm} 2013982$

[18] Akar E., Altınışık A., Seki Y.: Preparation of pH- and ionic-strength responsive biodegradable fumaric acid crosslinked carboxymethyl cellulose. Carbohydrate Polymers, 90, 1634-1641 (2012).

DOI: $10.1016 /$ j.carbpol.2012.07.043

[19] Gorgieva S., Kokol V.: Synthesis and application of new temperature-responsive hydrogels based on carboxymethyl and hydroxyethyl cellulose derivatives for the functional finishing of cotton knitwear. Carbohydrate Polymers, 85, 664-673 (2011).

DOI: $10.1016 /$ j.carbpol.2011.03.037

[20] Ekici S.: Intelligent poly( $N$-isopropylacrylamide)-carboxymethyl cellulose full interpenetrating polymeric networks for protein adsorption studies. Journal of Materials Science, 46, 2843-2850 (2011).

DOI: $10.1007 / \mathrm{s} 10853-010-5158-0$

[21] Wang W. B., Wang A. Q.: Preparation, swelling, and stimuli-responsive characteristics of superabsorbent nanocomposites based on carboxymethyl cellulose and rectorite. Polymers for Advanced Technologies, 22, 1602-1611 (2011).

DOI: $10.1002 /$ pat. 1647 
[22] Dhar N., Akhlaghi S. P., Tam K. C.: Biodegradable and biocompatible polyampholyte microgels derived from chitosan, carboxymethyl cellulose and modified methyl cellulose. Carbohydrate Polymers, 87, 101-109 (2012). DOI: 10.1016/j.carbpol.2011.07.022

[23] Kesselman L. R. B., Shinwary S., Selvaganapathy P. R., Hoare T.: Synthesis of monodisperse, covalently cross-linked, degradable 'smart' microgels using microfluidics. Small, 8, 1092-1098 (2012).

DOI: $10.1002 / \mathrm{smll} .201102113$

[24] Kobayashi S., Uyama H., Kalra B.: Enzymatic polymerization. Chemical Reviews, 101, 3793-3813 (2001). DOI: $10.1021 / \mathrm{cr} 9901211$

[25] Kurisawa M., Chung J. E., Yang Y. Y., Gao S. J., Uyama H.: Injectable biodegradable hydrogels composed of hyaluronic acid-tyramine conjugates for drug delivery and tissue engineering. Chemical Communications, 34, 4312-4314 (2005). DOI: $10.1039 / \mathrm{B} 506989 \mathrm{~K}$

[26] DeVolder R., Antoniadou E., Kong H. J.: Enzymatically cross-linked injectable alginate-g-pyrrole hydrogels for neovascularization. Journal of Controlled Release, 172, 30-37 (2013). DOI: $10.1016 / \mathrm{j} . j \mathrm{jconrel} .2013 .07 .010$
[27] Ke Y., Liu G. S., Guo T., Zhang Y., Li C., Xue W., Wu G., Wang J., Du C.: Size controlling of monodisperse carboxymethyl cellulose microparticles via a microfluidic process. Journal of Applied Polymer Science, 131, 40663 (2014).

DOI: 10.1002/app.40663

[28] Darr A., Calabro A.: Synthesis and characterization of tyramine-based hyaluronan hydrogels. Journal of Materials Science: Materials in Medicine, 20, 33-44 (2009). DOI: $10.1007 / \mathrm{s} 10856-008-3540-0$

[29] Castillo J. J., Torres M. H., Molina D. R., CastilloLeón J., Svendsen W. E., Escobar P., Martínez F.: Monitoring the functionalization of single-walled carbon nanotubes with chitosan and folic acid by two-dimensional diffusion-ordered NMR. Carbon, 50, 26912697 (2012).

DOI: $10.1016 /$ j.carbon.2012.02.010

[30] Atkinson B. L., Fantle K. S., Benedict J. J., Huffer W. E., Gutierrez-Hartmann A.: Combination of osteoinductive bone proteins differentiates mesenchymal $\mathrm{C} 3 \mathrm{H} /$ $10 \mathrm{~T} 1 / 2$ cells specifically to the cartilage lineage. Journal of Cellular Biochemistry, 65, 325-339 (1997).

DOI: 10.1002/(SICI)1097-4644(19970601)65:3<325:: AID-JCB3>3.0.CO;2-U 